\title{
Adolescent Understanding and Acceptance of the HPV Vaccination in an Underserved Population in New York City
}

\author{
Jill Blumenthal, ${ }^{1}$ Melissa K. Frey, ${ }^{2}$ Michael J. Worley Jr., ${ }^{3}$ Nana E. Tchabo, ${ }^{4}$ \\ Karen Soren, ${ }^{5}$ and Brian M. Slomovitz ${ }^{4}$ \\ ${ }^{1}$ Department of Internal Medicine, New York Presbyterian Hospital-Weill Cornell Medical College, New York, NY 10021, USA \\ ${ }^{2}$ Department of Obstetrics and Gynecology, New York Presbyterian Hospital-Weill Cornell Medical College, 525 East 68th Street, \\ New York, NY 10021, USA \\ ${ }^{3}$ Department Obstetrics and Gynecology, Brigham and Women's Hospital, Boston, MA 02115, USA \\ ${ }^{4}$ Department of Obstetrics and Gynecology, Morristown Memorial Hospital, Morristown, NJ 07960, USA \\ ${ }^{5}$ Department of Pediatrics, Columbia University Medical Center and New York Presbyterian Morgan Stanley Children's Hospital, \\ New York, NY 10032, USA
}

Correspondence should be addressed to Brian M. Slomovitz, brian.slomovitz@atlantichealth.org

Received 12 June 2011; Revised 8 August 2011; Accepted 23 August 2011

Academic Editor: Adhemar Longatto-Filho

Copyright (c) 2012 Jill Blumenthal et al. This is an open access article distributed under the Creative Commons Attribution License, which permits unrestricted use, distribution, and reproduction in any medium, provided the original work is properly cited.

\begin{abstract}
Background. HPV vaccination may prevent thousands of cases of cervical cancer. We aimed to evaluate the understanding and acceptance of the HPV vaccine among adolescents. Methods. A questionnaire was distributed to adolescents at health clinics affiliated with a large urban hospital system to determine knowledge pertaining to sexually transmitted diseases and acceptance of the HPV vaccine. Results. 223 adolescents completed the survey. 28\% were male, and $70 \%$ were female. The mean age for respondents was 16 years old. Adolescents who had received the HPV vaccine were more likely to be female and to have heard of cervical cancer and Pap testing. Of the 143 adolescents who had not yet been vaccinated, only $4 \%$ believed that they were at risk of HPV infection and 52\% were willing to be vaccinated. Conclusions. Surveyed adolescents demonstrated a marginal willingness to receive the HPV vaccine and a lack of awareness of personal risk for acquiring HPV.
\end{abstract}

\section{Introduction}

Approximately 20 million people in the United States are infected with genital human papillomavirus (HPV) [1]. An estimated 5.5 million people will acquire a new genital HPV infection each year, and the incidence of infection is highest among sexually active adolescent girls and young women between the age of 18 and 28 years old. It has been reported that $37 \%$ of males and $28 \%$ of females in the ninth grade have had sexual intercourse and $7 \%$ of students had sexual intercourse before the age of 13 [2]. Therefore, HPV vaccination ideally would be directed toward preadolescents and young adolescents in an effort to provide the greatest public health benefit offered by a prophylactic HPV vaccine.

It is predicted that HPV vaccination will prevent thousands of cases of cervical cancer worldwide. In addition, the emotional stress and economic burden associated with abnormal Papanicolaou test results and the treatment of preinvasive cervical lesions will be greatly reduced. The quadrivalent HPV vaccine (Gardasil, Merck \& Co.) was found to have $97 \%$ efficacy at preventing HPV 16 and/or 18 related cervical intraepithelial neoplasia 2 or 3, adenocarcinoma in situ, and cervical cancer [3]. The quadrivalent HPV is approved for use in males and females between 9 and 26 years of age. On October 16, 2009, the FDA approved a recombinant HPV bivalent vaccine (Cervarix, Glaxo Smith Kline Biologicals) to prevent cervical cancer and precancerous lesions caused by HPV types 16 and 18 . This HPV vaccine is approved for use in females between 10 and 25 years of age and is the second HPV vaccine licensed for use in females in the United States.

Until recently, studies of women and young adults have shown poor levels of knowledge about HPV, Papanicolaou smear testing, and cervical cancer $[4,5]$. Current research 
indicates that understanding has improved. However, knowledge of some relevant issues is higher than others. A review by Brewer and Fazekas reported that only $21 \%$ of respondents knew that HPV is common, 59\% knew the purpose of a Papanicolaou smear, and $68 \%$ knew that HPV is a sexually transmitted infection [6]. In addition, awareness of HPV among a racially diverse sample of young adults, aged 18-26 years old, was found to be relatively high, with more than $75 \%$ of study participants indicating that they had heard of HPV from various sources [7]. However, another recent study examining the acceptability of the HPV vaccination among Latina immigrants and African American women found that $61 \%$ of Latinas and $78 \%$ of African Americans had never heard about HPV [8].

Continuing, several studies indicate that most parents, especially with proper knowledge of HPV and the vaccine, are willing to accept the HPV vaccine for their children [9-12]. Healthcare providers are an important source of information for parents and children, and studies show that they generally have a positive attitude towards recommending HPV vaccination $[13,14]$. The vaccination series can be started beginning at 9 years old, and the Advisory Committee on Immunization Practices currently recommends routine vaccination of females aged 11 or 12 years with three doses of HPV vaccine. In addition, the quadrivalent HPV vaccination has been approved in males aged 9 through 26 years to reduce their likelihood of acquiring genital warts. Ideally, vaccination should be administered before potential exposure to HPV through sexual contact [15].

The purpose of this study was to evaluate the understanding and potential acceptance of the HPV vaccine by adolescents aged 13 to 18 years at adolescent health clinics affiliated with New York Presbyterian Hospital. Although previous research shows that most adolescents, parents, and health care providers are willing to accept universal vaccination for themselves, their attitudes and knowledge regarding the vaccine have yet to be evaluated. Improved knowledge of adolescent understanding and acceptance of the HPV vaccine would help practitioners provide appropriate and useful information to parents, providers, and adolescents when making the decision to vaccinate.

\section{Materials and Methods}

Approval for this study was received from the institutional review board. We administered a questionnaire to all adolescent patients (defined as between 13 and 18 years of age) awaiting annual well-patient medical examinations in adolescent health clinics affiliated with Weill Cornell Medical College and Columbia University Medical Center. These health clinics provide affordable, comprehensive services to a diverse patient population including underserved populations from each of the five boroughs in the New York City area. The adolescent patient was provided the questionnaire in English and/or Spanish. We could not predict the number of adolescent patients who would be interested in participating in this study, and therefore prior to study initiation we defined the survey collection period as September 1, 2007 through February 1, 2008 with the goal
TABLE 1: Description of adolescent characteristics.

\begin{tabular}{|c|c|c|}
\hline & Variable & $n(\%)$ \\
\hline Mean age & & 15.9 (range 13-18) \\
\hline \multicolumn{3}{|l|}{ Sex } \\
\hline & Male & $62(27.8)$ \\
\hline & Female & $155(69.5)$ \\
\hline & Blank & $4(1.8)$ \\
\hline \multicolumn{3}{|l|}{ Race } \\
\hline & African American & $47(21.1)$ \\
\hline & Native American/Aleutian/Eskimo & $1(0.4)$ \\
\hline & Hispanic & $145(65.0)$ \\
\hline & Asian & $3(1.3)$ \\
\hline & Caucasian & $6(8.5)$ \\
\hline & Other & $19(8.5)$ \\
\hline & Blank & $2(0.9)$ \\
\hline \multicolumn{3}{|l|}{ Language } \\
\hline & English & $210(94.2)$ \\
\hline & Spanish & $11(4.9)$ \\
\hline & Blank & $2(0.9)$ \\
\hline \multicolumn{3}{|l|}{ Religion } \\
\hline & Catholic & $132(59.2)$ \\
\hline & Jewish & $1(0.4)$ \\
\hline & Buddhist & $2(0.9)$ \\
\hline & Protestant & $3(1.3)$ \\
\hline & Muslim & $8(3.6)$ \\
\hline & Jehovah's Witness & $3(1.3)$ \\
\hline & No religion & $29(13.0)$ \\
\hline & Other & $39(17.5)$ \\
\hline & Blank & $6(2.7)$ \\
\hline
\end{tabular}

of collecting the maximum number of surveys possible. The research personnel emphasized that participation was voluntary, anonymous, and without incentive for questionnaire completion.

The questionnaire consisted of two parts; the first part elicited the adolescent's demographic information and knowledge pertaining to sexually transmitted diseases and vaccinations. When the first part was completed, the adolescent was provided with a second part that contained current facts about the HPV vaccine and cervical cancer, followed by questions specifically designed to ascertain adolescent acceptance of the vaccination. Adolescents whose primary language was neither English nor Spanish were excluded from the study since the questionnaire was self-administered and available only in English and Spanish.

Data were analyzed using commercially available software (SPSS version 16.0; SPSS, Inc., Chicago, IlL). A series of $\chi 2$ and Fisher's exact tests were used for comparison of proportions between "HPV vaccine status" and 15 other variables of interest (see Table 2) and "Willingness to receive the HPV vaccine" and 15 other variables of interest (see Table 3). A $P$ value of $<0.05$ was considered significant for all tests. For the series of 15 analyses, the sample sizes of 223 participants (HPV vaccine status) and 143 participants (willingness to be vaccinated) provided a mean power $>99.9 \%$ for detecting a difference between both whether the adolescent 
TABLE 2: HPV vaccine status.

\begin{tabular}{|c|c|c|c|c|c|c|c|}
\hline & Have $\mathrm{h}$ & V vaccine & Have no & IPV vaccine & Do $n$ & know & $P$ value \\
\hline & $\#$ & $\%$ & $\#$ & $\%$ & \# & $\%$ & \\
\hline Language & & & & & & & 1.000 \\
\hline English & 69 & $32.9 \%$ & 137 & $65.2 \%$ & 4 & $1.9 \%$ & \\
\hline Spanish & 4 & $36.4 \%$ & 7 & $63.6 \%$ & 0 & $0.0 \%$ & \\
\hline Age (mean) & & 16.08 & & 15.85 & & - & 0.311 \\
\hline Gender & & & & & & & $<0.001$ \\
\hline Male & 2 & $3.1 \%$ & 60 & $93.8 \%$ & 2 & $3.1 \%$ & \\
\hline Female & 71 & $45.2 \%$ & 84 & $53.5 \%$ & 2 & $1.3 \%$ & \\
\hline Race & & & & & & & 0.677 \\
\hline African American & 19 & $40.4 \%$ & 27 & $57.4 \%$ & 1 & $2.1 \%$ & \\
\hline Native American/Aleutian/Eskimo & 0 & $0.0 \%$ & 1 & $100.0 \%$ & 0 & $0.0 \%$ & \\
\hline Hispanic & 47 & $32.4 \%$ & 95 & $65.5 \%$ & 3 & $2.1 \%$ & \\
\hline Asian & 0 & $0.0 \%$ & 3 & $100.0 \%$ & 0 & $0.0 \%$ & \\
\hline White & 3 & $50.0 \%$ & 3 & $50.0 \%$ & 0 & $0.0 \%$ & \\
\hline Other & 4 & $21.1 \%$ & 15 & $78.9 \%$ & 0 & $0.0 \%$ & \\
\hline Religion & & & & & & & 0.708 \\
\hline Catholic & 44 & $33.3 \%$ & 86 & $65.2 \%$ & 2 & $1.5 \%$ & \\
\hline Jewish & 1 & $100.0 \%$ & 0 & $0.0 \%$ & 0 & $0.0 \%$ & \\
\hline Buddhist & 0 & $0.0 \%$ & 2 & $100.0 \%$ & 0 & $0.0 \%$ & \\
\hline Protestant & 0 & $0.0 \%$ & 3 & $100.0 \%$ & 0 & $0.0 \%$ & \\
\hline No Religion & 11 & $37.9 \%$ & 17 & $58.6 \%$ & 1 & $3.4 \%$ & \\
\hline Muslim & 2 & $25.0 \%$ & 6 & $75.0 \%$ & 0 & $0.0 \%$ & \\
\hline Jehovah's Witness & 0 & $0.0 \%$ & 3 & $100.0 \%$ & 0 & $0.0 \%$ & \\
\hline Other & 15 & $38.5 \%$ & 23 & $59.0 \%$ & 1 & $2.6 \%$ & \\
\hline Blank & 0 & $0.0 \%$ & 4 & $100.0 \%$ & 0 & $0.0 \%$ & \\
\hline Mother's completed level of education & & & & & & & 0.031 \\
\hline Less than high school & 25 & $41.0 \%$ & 36 & $59.0 \%$ & 0 & $0.0 \%$ & \\
\hline High school/GED & 19 & $22.9 \%$ & 62 & $74.7 \%$ & 2 & $2.4 \%$ & \\
\hline College & 21 & $47.7 \%$ & 23 & $52.3 \%$ & 0 & $0.0 \%$ & \\
\hline Professional degree & 4 & $22.2 \%$ & 13 & $72.2 \%$ & 1 & $5.6 \%$ & \\
\hline Other & 1 & $16.7 \%$ & 5 & $83.3 \%$ & 0 & $0.0 \%$ & \\
\hline Blank & 3 & $33.3 \%$ & 5 & $55.6 \%$ & 1 & $11.1 \%$ & \\
\hline Father's completed level of education & & & & & & & 0.287 \\
\hline$<$ high school & 25 & $37.9 \%$ & 41 & $62.1 \%$ & 0 & $0.0 \%$ & \\
\hline High school/GED & 24 & $31.2 \%$ & 50 & $64.9 \%$ & 3 & $3.9 \%$ & \\
\hline College & 7 & $26.9 \%$ & 18 & $69.2 \%$ & 1 & $3.8 \%$ & \\
\hline Professional degree & 1 & $10.0 \%$ & 9 & $90.0 \%$ & 0 & $0.0 \%$ & \\
\hline Other & 6 & $54.5 \%$ & 5 & $45.5 \%$ & 0 & $0.0 \%$ & \\
\hline Blank & 10 & $32.3 \%$ & 21 & $67.7 \%$ & 0 & $0.0 \%$ & \\
\hline Has an older sibling who received the HPV vaccine & & & & & & & 1 \\
\hline Yes & 44 & $34.1 \%$ & 83 & $64.3 \%$ & 2 & $1.6 \%$ & \\
\hline No & 27 & $34.6 \%$ & 50 & $64.1 \%$ & 1 & $1.3 \%$ & \\
\hline Blank & 0 & $0.0 \%$ & 1 & $1.0 \%$ & 0 & $0.0 \%$ & \\
\hline Unclear & 2 & $15.4 \%$ & 10 & $76.9 \%$ & 1 & $7.7 \%$ & \\
\hline Has a younger sibling who received the HPV vaccine & & & & & & & 1 \\
\hline Yes & 40 & $33.1 \%$ & 79 & $65.3 \%$ & 2 & $1.7 \%$ & \\
\hline No & 29 & $34.1 \%$ & 55 & $64.7 \%$ & 1 & $1.2 \%$ & \\
\hline Blank & 0 & $0.0 \%$ & 1 & $100.0 \%$ & 0 & $0.0 \%$ & \\
\hline Unclear & 4 & $28.6 \%$ & 9 & $64.3 \%$ & 1 & $7.1 \%$ & \\
\hline Heard of cervical cancer & & & & & & & $<0.001$ \\
\hline Yes & 69 & $41.1 \%$ & 97 & $57.7 \%$ & 2 & $1.2 \%$ & \\
\hline No & 4 & $7.5 \%$ & 47 & $88.7 \%$ & 2 & $3.8 \%$ & \\
\hline
\end{tabular}


TABle 2: Continued.

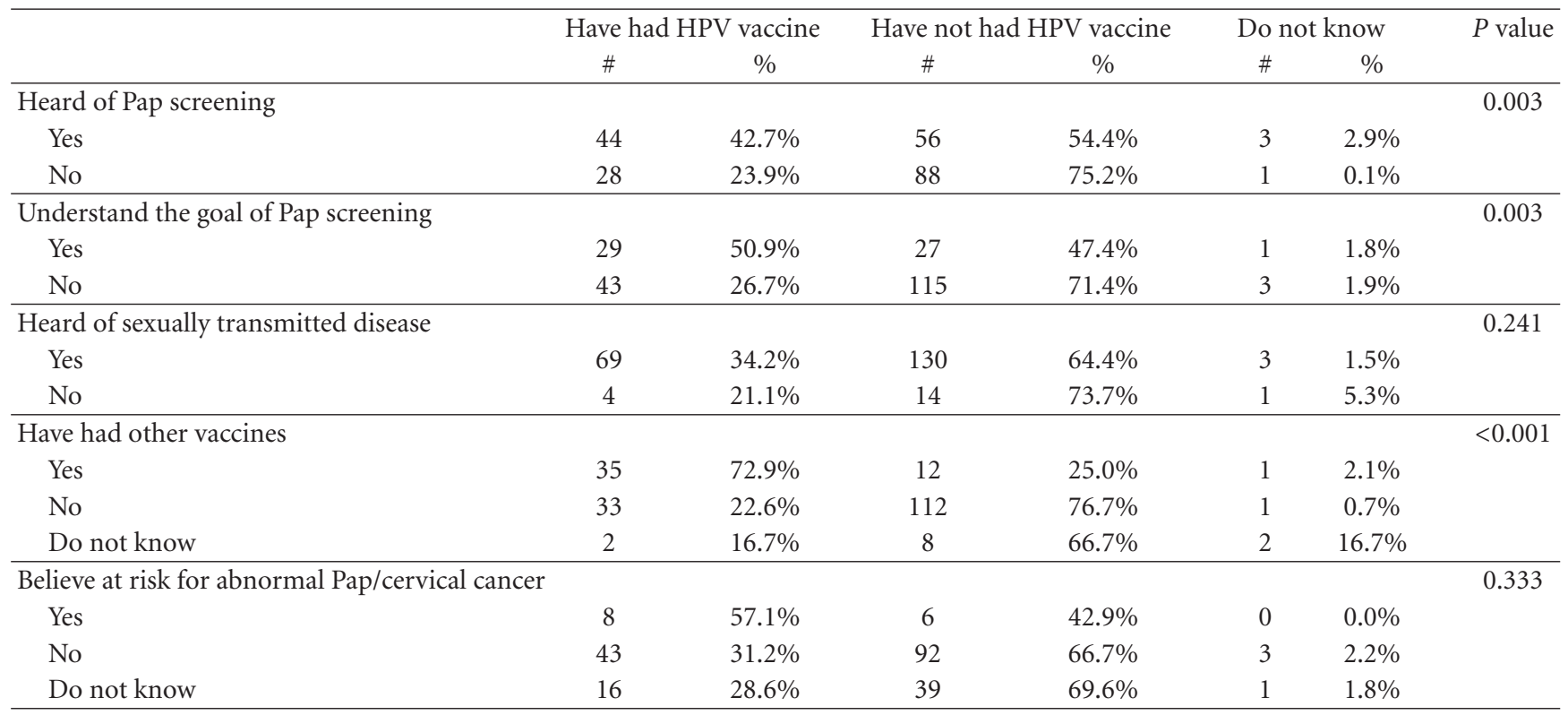

had been vaccinated and whether the adolescent was willing to receive the HPV vaccine and the respective variable, using 2 -tailed test with statistical significance defined as $P<0.05$.

\section{Results}

Of the 223 adolescents who completed the survey, 28\% were male and $70 \%$ were female $(2 \%$ did not respond to the question). The mean age of respondents was 16 years old (range 13-18). The demographics of adolescents including in this study are displayed in Table 1 . A majority of adolescents surveyed $(168,75 \%)$ stated that they had prior knowledge of cervical cancer. However, a smaller percentage of adolescents (103, 46\%) acknowledged prior knowledge of what a "Pap smear" was, and only 57 respondents (26\%) were aware that the Pap smear was used to screen for cervical cancer. 5\% (11) of respondents reported knowing someone who had/has cervical cancer, and 91\% (202) were familiar with the term "sexually transmitted disease" or "STD".

Of the 223 adolescent surveyed, 33\% stated that they had received the HPV vaccine, $64 \%$ had not had the vaccine, and $3 \%$ where not sure. Among the 143 adolescents who had not yet been vaccinated, $52 \%$ were willing to get the HPV vaccine, $12 \%$ were not willing, and $36 \%$ were unsure. Of the 143 adolescents who had not yet been vaccinated, only $4 \%$ believed that they were at risk for being exposed to HPV.

Of the 73 respondents that stated that they had received the HPV vaccine, the mean age was 16 years old (range 1318). Female respondents were more likely to have received the HPV vaccine than male respondents (45\% versus $3 \%$, $P<0.001)$. HPV vaccination status was not significantly associated with language, race, religion, or having younger or older siblings who had received the HPV vaccine. HPV vaccine status was associated with knowledge of cervical cancer $(41 \%$ of those who had heard of cervical cancer were vaccinated), knowledge of Pap screening (43\% who had heard of Pap screening were vaccinated), and having had other vaccines $(73 \%$ of those who had received other vaccines were vaccinated) (Table 2).

Among the adolescents who had not yet received the HPV vaccine, $58 \%$ of females and $42 \%$ of males were willing to be vaccinated; however this difference was not statistically significant. In addition, 53\% of Hispanic adolescents and $56 \%$ of African American adolescents were willing to accept vaccination. There was no association with willingness to receive the vaccine and gender, race, religion, language, having vaccinated siblings, knowledge of cervical cancer, Pap screening, sexually transmitted disease, or any other studied variable.

\section{Discussion}

The current study reveals only a marginal willingness of teenagers to accept the HPV vaccine. The majority of data to date suggest that young women are interested in vaccines that prevent HPV and other sexually transmitted infections. However, most of these studies have been conducted with women and men of 18 years of age or older. Holcomb et al. found that women are interested in learning about HPV, how the virus is transmitted, and how women can prevent becoming infected [16]. In 2001, a study of women recruited from community and clinical sites displayed that roughly $85 \%$ of participants indicated an intention to receive an HPV vaccine for cervical cancer prevention once it became available [17]. A study of young, Australian, men and women aged 18-23 years old showed a high vaccine acceptance despite inadequate knowledge of HPV infection [18]. Another study of male and female college students found an overall acceptance rate of the HPV vaccine of $74 \%$. In this study, although females were more likely to have already been vaccinated, gender did not affect vaccine acceptance among unvaccinated adolescents [19]. In contrast 
TABLE 3: Willingness to receive the HPV vaccine among adolescent who have not yet been vaccinated.

\begin{tabular}{|c|c|c|c|c|c|c|c|}
\hline & \multicolumn{2}{|c|}{ Yes } & \multicolumn{2}{|c|}{$\mathrm{No}$} & \multicolumn{2}{|c|}{ Do not know } & \multirow[t]{2}{*}{$P$} \\
\hline & $\#$ & $\%$ & $\#$ & $\%$ & $\#$ & $\%$ & \\
\hline$\overline{\text { Language }}$ & & & & & & & 0.873 \\
\hline English & 71 & $52.2 \%$ & 17 & $12.5 \%$ & 48 & $35.3 \%$ & \\
\hline Spanish & 3 & $42.9 \%$ & 1 & $14.3 \%$ & 3 & $42.9 \%$ & \\
\hline Age (mean) & 74 & $1605.00 \%$ & 18 & 16.06 & & & 0.997 \\
\hline Gender & & & & & & & 0.126 \\
\hline Male & 25 & $42.4 \%$ & 10 & $16.9 \%$ & 24 & $40.7 \%$ & \\
\hline Female & 49 & $58.3 \%$ & 8 & $9.5 \%$ & 27 & $32.1 \%$ & \\
\hline Race & & & & & & & 0.062 \\
\hline African American & 15 & $55.6 \%$ & 0 & $0.0 \%$ & 12 & $44.4 \%$ & \\
\hline Native American/Aleutian/Eskimo & 0 & $0.0 \%$ & 1 & $100.0 \%$ & 0 & $0.0 \%$ & \\
\hline Hispanic & 50 & $52.6 \%$ & 13 & $13.7 \%$ & 32 & $33.7 \%$ & \\
\hline Asian & 0 & $0.0 \%$ & 0 & $0.0 \%$ & 2 & $100.0 \%$ & \\
\hline White & 1 & $33.3 \%$ & 1 & $33.3 \%$ & 1 & $33.3 \%$ & \\
\hline Other & 8 & $53.3 \%$ & 3 & $20.0 \%$ & 4 & $26.7 \%$ & \\
\hline Religion & & & & & & & 0.569 \\
\hline Catholic & 48 & $55.8 \%$ & 10 & $11.6 \%$ & 28 & $32.6 \%$ & \\
\hline Buddhist & 0 & $0.0 \%$ & 0 & $0.0 \%$ & 1 & $100.0 \%$ & \\
\hline Protestant & 1 & $33.3 \%$ & 1 & $33.3 \%$ & 1 & $33.3 \%$ & \\
\hline No Religion & 10 & $58.8 \%$ & 2 & $11.8 \%$ & 5 & $29.4 \%$ & \\
\hline Muslim & 1 & $16.7 \%$ & 1 & $16.7 \%$ & 4 & $66.7 \%$ & \\
\hline Jehovah's Witness & 1 & $33.3 \%$ & 1 & $33.3 \%$ & 1 & $33.3 \%$ & \\
\hline Other & 11 & $47.8 \%$ & 3 & $13.0 \%$ & 9 & $39.1 \%$ & \\
\hline Blank & 2 & $50.0 \%$ & 0 & $0.0 \%$ & 2 & $50.0 \%$ & \\
\hline Mother's completed level of education & & & & & & & 0.094 \\
\hline$<$ high school & 21 & $60.0 \%$ & 3 & $8.6 \%$ & 11 & $31.4 \%$ & \\
\hline High school/GED & 35 & $56.5 \%$ & 9 & $14.5 \%$ & 18 & $29.0 \%$ & \\
\hline College & 10 & $43.5 \%$ & 2 & $8.7 \%$ & 11 & $47.8 \%$ & \\
\hline Professional degree & 7 & $53.8 \%$ & 3 & $23.1 \%$ & 3 & $23.1 \%$ & \\
\hline Other & 0 & $0.0 \%$ & 0 & $0.0 \%$ & 5 & $100.0 \%$ & \\
\hline Blank & 1 & $20.0 \%$ & 1 & $20.0 \%$ & 3 & $60.0 \%$ & \\
\hline Father's completed level of education & & & & & & & 0.204 \\
\hline$<$ high school & 25 & $62.5 \%$ & 2 & $5.0 \%$ & 13 & $32.5 \%$ & \\
\hline High school/GED & 21 & $42.0 \%$ & 8 & $16.0 \%$ & 21 & $42.0 \%$ & \\
\hline College & 6 & $33.3 \%$ & 3 & $16.7 \%$ & 9 & $50.0 \%$ & \\
\hline Professional degree & 4 & $44.4 \%$ & 3 & $33.3 \%$ & 2 & $22.2 \%$ & \\
\hline Other & 3 & $60.0 \%$ & 0 & $0.0 \%$ & 2 & $40.0 \%$ & \\
\hline Blank & 15 & $71.4 \%$ & 2 & $9.5 \%$ & 4 & $19.0 \%$ & \\
\hline Has an older sibling who received the HPV vaccine & & & & & & & 0.683 \\
\hline Yes & 41 & $49.4 \%$ & 13 & $15.7 \%$ & 29 & $34.9 \%$ & \\
\hline No & 26 & $52.0 \%$ & 5 & $10.0 \%$ & 19 & $38.0 \%$ & \\
\hline Blank & 1 & $100.0 \%$ & 0 & $0.0 \%$ & 0 & $0.0 \%$ & \\
\hline Unclear & 6 & $66.7 \%$ & 0 & $0.0 \%$ & 3 & $33.3 \%$ & \\
\hline Has a younger sibling who received the HPV vaccine & & & & & & & 0.183 \\
\hline Yes & 41 & $51.9 \%$ & 7 & $8.9 \%$ & 31 & $39.2 \%$ & \\
\hline No & 26 & $47.3 \%$ & 11 & $20.0 \%$ & 18 & $32.7 \%$ & \\
\hline Blank & 1 & $100.0 \%$ & 0 & $0.0 \%$ & 0 & $0.0 \%$ & \\
\hline Unclear & 6 & $75.0 \%$ & 0 & $0.0 \%$ & 2 & $25.0 \%$ & \\
\hline Heard of cervical cancer & & & & & & & 0.111 \\
\hline Yes & 55 & $56.7 \%$ & 13 & $13.4 \%$ & 29 & $29.9 \%$ & \\
\hline No & 19 & $41.3 \%$ & 5 & $10.9 \%$ & 22 & $47.8 \%$ & \\
\hline
\end{tabular}


Table 3: Continued.

\begin{tabular}{|c|c|c|c|c|c|c|c|}
\hline & & & & & Do & ow & $P$ \\
\hline & $\#$ & $\%$ & \# & $\%$ & \# & $\%$ & \\
\hline Heard of Pap screening & & & & & & & 0.131 \\
\hline Yes & 33 & $58.9 \%$ & 6 & $10.7 \%$ & 17 & $30.4 \%$ & \\
\hline No & 41 & $47.1 \%$ & 12 & $13.8 \%$ & 34 & $39.1 \%$ & \\
\hline Know the use of Pap & & & & & & & 0.451 \\
\hline Yes & 16 & $59.3 \%$ & 4 & $14.8 \%$ & 7 & $25.9 \%$ & \\
\hline No & 56 & $49.1 \%$ & 14 & $12.3 \%$ & 44 & $38.6 \%$ & \\
\hline Heard of sexually transmitted disease & & & & & & & 0.447 \\
\hline Yes & 69 & $53.5 \%$ & 16 & $12.4 \%$ & 44 & $34.1 \%$ & \\
\hline No & 5 & $35.7 \%$ & 2 & $14.3 \%$ & 7 & $50.0 \%$ & \\
\hline Have had other vaccines & & & & & & & 0.319 \\
\hline Yes & 9 & $75.0 \%$ & 1 & $8.3 \%$ & 2 & $16.7 \%$ & \\
\hline No & 53 & $47.7 \%$ & 17 & $15.3 \%$ & 41 & $36.9 \%$ & \\
\hline Do not know & 6 & $50.0 \%$ & 0 & $0.0 \%$ & 6 & $50.0 \%$ & \\
\hline Believe at risk for abnormal Pap/cervical cancer & & & & & & & 0.3 \\
\hline Yes & 3 & $50.0 \%$ & 2 & $33.3 \%$ & 1 & $16.7 \%$ & \\
\hline No & 46 & $50.0 \%$ & 13 & $14.1 \%$ & 33 & $35.9 \%$ & \\
\hline Do not know & 21 & $55.3 \%$ & 2 & $5.3 \%$ & 15 & $39.5 \%$ & \\
\hline
\end{tabular}

to most of the data available in the literature, this current review sampled a younger population. We found a generalized lack of awareness of HPV among adolescents. Although the majority of adolescents had heard of cervical cancer (75\%), only $46 \%$ knew what a Pap smear was, and only $26 \%$ knew that the Pap smear is a screening test for cervical cancer. Furthermore, only $4 \%$ of the adolescents surveyed who had not yet received the HPV vaccine believed that they were at risk for HPV infection. The lack of awareness about cervical cancer screening and underestimated risk of HPV risk likely contributes to the limited willingness of the adolescents surveyed to accept the HPV vaccine for themselves.

Many of the adolescents stated that they would seek advice from a parent or physician when deciding whether or not to accept the HPV vaccine. Interestingly, we found no significant association between having had the HPV vaccine or willingness to receive the vaccine and the level of education of the adolescent's parents. There was also no association between having younger or older siblings who had been vaccinated and having had the HPV vaccine or willingness to receive the vaccine. Many studies have shown that most parents are willing to accept the HPV vaccine for their children. A recent study, postlicensure of the vaccine, evaluated mothers of children in primary and secondary schools in England and found that $75 \%$ of mothers would accept the HPV vaccine for their daughter. Acceptance was higher in mothers who had experienced cancer in their families, had older daughters, perceived approval from their husbands/partners, and believed vaccine acceptance would be more normative [20]. Another postlicensure study used a random-digit-dial telephone survey to examine the likelihood of parental acceptance of the HPV vaccination for young adolescent girls in California. Within this sample, 75\% of parents were likely to vaccinate a daughter before age 13 . Hispanic parents were more likely to accept vaccination than were non-Hispanic parents, and African American and Asian
American parents were the least likely to accept vaccination [21]. Overall, parental attitude and acceptance studies suggest a great deal of parental interest in HPV vaccination for their adolescent children. Healthcare providers may be able to encourage participation in HPV vaccine programs by bolstering parents' underlying desire to protect their children, as recommendation by a healthcare provider is a crucial prompt for vaccination.

Healthcare providers are an important source of information for parents and children, and studies show that they generally have a positive attitude towards recommending an HPV vaccination. One study of 207 fellows of the American College of Obstetricians and Gynecologists found a fairly positive disposition towards recommending the HPV vaccine, with a mean rating for vaccine recommendation of 79 out of 100 [22]. Similarly, 224 nurse practitioners had a favorable attitude about HPV vaccine recommendation, with a mean rating of 72 out of 100 [23]. Our study reveals that knowledge of cervical cancer and Pap screening is associated with having had the HPV vaccine, however interestingly not with willingness to accept the vaccine among those not yet vaccinated.

Previous studies have shown that knowledge of personal risk is generally limited with regard to sexually transmitted infections. A study of sexually active heterosexual college students found that personal risk of contracting Acquires Immune Deficiency Syndrome was estimated to be significantly lower than risk for each of a set of hypothetical persons who varied in degree of similarity to respondents [24]. In a study of university students in the United Kingdom, screening for chlamydia was limited, and perception of personal risk was poor [25]. In a pilot study among Australian university students, even though the majority of students were comfortable with opportunistic testing for chlamydia by their general practitioner, the likelihood of being tested in the upcoming year for most students was low, as was 
personal concern about chlamydia infection [26]. With regard to HPV, a recent study of Australian women with diverse sexual orientation, found that the majority of women had risk factors for HPV but few felt personally at risk of acquiring infection [27]. Among the 143 adolescents in our study who had not yet received the HPV vaccine, only $4 \%$ believed that they were at risk for being exposed to HPV. The very low personal risk perception for HPV suggests the need for targeted education for this group regarding HPV transmission and prevention.

Study limitations should be considered when interpreting the present findings. Participants were recruited from a hospital-based adolescent health clinic serving a racially and ethnically diverse, predominantly low-income, population. As a result, the findings may not be applicable to all adolescents in the United States. In order to include 13 and 14 years old in this study at an adolescent health clinic, we were unable to ask certain direct questions, including "Are you sexually active?". The answer to this question may have provided more information regarding age of sexual activity in the current study population and would allow direct comparison of these results with a personal risk perception question. In addition, because the time frame was not stated explicitly in the question regarding personal risk, it is unclear whether participants were rating their risk of HPV infection at present, in the immediate future, or over their lifetime, which would also affect the accuracy of their ratings.

\section{Conclusion}

It is clear that education will play an important role in the implementation of an HPV vaccination program. In this study, only $53 \%$ of adolescents who had not yet received the HPV vaccine were willing to be vaccinated, and lack of education likely contributes to this hesitancy. Healthcare providers must be proactive in educating and discussing benefits of vaccination. Based on factors affecting vaccine acceptability, HPV vaccine programs in the United States should emphasize high vaccine effectiveness, the high likelihood of HPV infection, physician recommendations, and address barriers to vaccination. It is important to educate patients that the vaccine is most effective prior to sexual activity and HPV exposure. However, the vaccine does not replace routine screening for cervical cancer or the need for education about continued cervical cancer screening. Thus, it is essential for healthcare providers to offer guidance about the ongoing need for screening. Future studies will be necessary to evaluate public health issues that arise once the HPV vaccination programs have been established more extensively.

\section{Conflict of Interests}

The authors declare that there is no conflict of interests.

\section{Authors' Contribution}

J. Blumenthal and M. K. Frey contributed equally to the work.

\section{References}

[1] H. Weinstock, S. Berman, and W. Cates Jr., "Sexually transmitted diseases among American youth: incidence and prevalence estimates, 2000," Perspectives on Sexual and Reproductive Health, vol. 36, no. 1, pp. 6-10, 2004.

[2] Centers for Disease Control, "Youth risk behavior surveillance-United States, 2003," Morbidity and Mortality Weekly Report, vol. 53, no. 2, pp. 1-96, 2004.

[3] F. E. Skjeldestad, "Prophylactic quadrivalent human papillomavirus (HPV) (types 6, 11, 16, 18) L1 virus-like particle VLP) vaccine (Gardasil) reduces cervical intraepithelial neoplasia (CIN) 2/3 risk," in Proceedings of the 43rd Annual Meeting of the Infectious Disease Society of America, San Francisco, Calif, USA, October 2005.

[4] D. R. Blake, B. R. Weber, and K. E. Fletcher, "Adolescent and young adult women's misunderstanding of the term Pap smear," Archives of Pediatrics and Adolescent Medicine, vol. 158, no. 10, pp. 966-970, 2004.

[5] M. Pitts and T. Clarke, "Human papillomavirus infections and risks of cervical cancer: what do women know?" Health Education Research, vol. 17, no. 6, pp. 706-714, 2002.

[6] N. T. Brewer and K. I. Fazekas, "Predictors of HPV vaccine acceptability: a theory-informed, systematic review," Preventive Medicine, vol. 45, no. 2-3, pp. 107-114, 2007.

[7] M. A. Gerend and Z. F. Magloire, "Awareness, knowledge, and beliefs about human papillomavirus in a racially diverse sample of young adults," Journal of Adolescent Health, vol. 42, no. 3, pp. 237-242, 2008.

[8] I. C. Scarinci, I. C. Garcés-Palacio, and E. E. Partridge, "An examination of acceptability of HPV vaccination among African American women and Latina immigrants," Journal of Women's Health, vol. 16, no. 8, pp. 1224-1233, 2007.

[9] R. M. Mays, L. A. Sturm, and G. D. Zimet, "Parental perspectives on vaccinating children against sexually transmitted infections," Social Science and Medicine, vol. 58, no. 7, pp. 1405-1413, 2004.

[10] E. Lazcano-Ponce, L. Rivera, E. Arillo-Santillán, J. Salmerón, M. Hernández-Avila, and N. Muñoz, "Acceptability of a human papillomavirus (HPV) trial vaccine among mothers of adolescents in Cuernavaca, Mexico," Archives of Medical Research, vol. 32, no. 3, pp. 243-247, 2001.

[11] B. Slomovitz, C. C. Sun, M. Frumovitz et al., "Are women ready for the HPV vaccine?" Gynecologic Oncology, vol. 103, no. 1, pp. 151-154, 2006.

[12] K. Davis, E. D. Dickman, D. Ferris, and J. K. Dias, "Human papillomavirus vaccine acceptability among parents of 10to 15-year-old adolescents," Journal of Lower Genital Tract Disease, vol. 8, no. 3, pp. 188-194, 2004.

[13] J. C. Raley, K. A. Followwill, G. D. Zimet, and K. A. Ault, "Gynecologists' attitudes regarding human papilloma virus vaccination: a survey of Fellows of the American College of Obstetricians and Gynecologists," Infectious Disease in Obstetrics and Gynecology, vol. 12, no. 3-4, pp. 127-133, 2004.

[14] R. M. Mays and G. D. Zimet, "Recommending STI vaccination to parents of adolescents: the attitudes of nurse practitioners," Sexually Transmitted Diseases, vol. 31, no. 7, pp. 428-432, 2004.

[15] Centers for Disease Control and Prevention, "FDA licensure of bivalent human papillomavirus vaccine (HPV2, Cervarix) for use in females and updated HPV vaccination recommendations from the advisory committee on immunization practices (ACIP)," Morbidity and Mortality Weekly Report, vol. 59, no. 20, pp. 626-629, 2010. 
[16] B. Holcomb, J. M. Bailey, K. Crawford, and M. T. Ruffin, "Adults' knowledge and behaviors related to human papillomavirus infection," Journal of the American Board of Family Practice, vol. 17, no. 1, pp. 26-31, 2004.

[17] J. A. Kahn, S. L. Rosenthal, T. Hamannn, and D. I. Bernstein, "Attitudes about human papillomavirus vaccine in young women," International Journal of STD and AIDS, vol. 14, no. 5, pp. 300-306, 2003.

[18] A. McClelland and P. Liamputtong, "Knowledge and acceptance of human papillomavirus vaccination: perspectives of young Australians living in Melbourne, Australia," Sexual Health, vol. 3, no. 2, pp. 95-101, 2006.

[19] C. W. Boehner, S. R. Howe, D. I. Bernstein, and S. L. Rosenthal, "Viral sexually transmitted disease vaccine acceptability among college students," Sexually Transmitted Diseases, vol. 30, no. 10, pp. 774-778, 2003.

[20] L. A. Marlow, J. Waller, and J. Wardle, "Parental attitudes to pre-pubertal HPV vaccination," Vaccine, vol. 25, no. 11, pp. 1945-1952, 2007.

[21] N. A. Constantine and P. Jerman, "Acceptance of human papillomavirus vaccination among Californian parents of daughters: a representative statewide analysis," Journal of Adolescent Health, vol. 40, no. 2, pp. 108-115, 2007.

[22] J. C. Raley, K. A. Followwill, G. D. Zimet, and K. A. Ault, “Gynecologists' attitudes regarding human papilloma virus vaccination: a survey of Fellows of the American College of Obstetricians and Gynecologists," Infectious Disease in Obstetrics and Gynecology, vol. 12, no. 3-4, pp. 127-133, 2004.

[23] R. M. Mays and G. D. Zimet, "Recommending STI vaccination to parents of adolescents: the attitudes of nurse practitioners," Sexually Transmitted Diseases, vol. 31, no. 7, pp. 428-432, 2004.

[24] S. E. Mickler, "Perceptions of vulnerability: impact on AIDSpreventive behavior among college adolescents," AIDS Education and Prevention, vol. 5, no. 1, pp. 43-53, 1993.

[25] A. Greaves, S. Lonsdale, S. Whinney, E. Hood, H. Mossop, and B. Olowokure, "University undergraduates' knowledge of chlamydia screening services and chlamydia infection following the introduction of a National Chlamydia Screening Programme," European Journal of Contraception and Reproductive Health Care, vol. 14, no. 1, pp. 61-68, 2009.

[26] B. Zakher and M. Kang, "Attitudes to chlamydia screening in general practice among Australian university students: a pilot study," Sexual Health, vol. 5, no. 4, pp. 359-363, 2008.

[27] R. McNair, J. Power, and S. Carr, "Comparing knowledge and perceived risk related to the human papilloma virus among Australian women of diverse sexual orientations," Australian and New Zealand Journal of Public Health, vol. 33, no. 1, pp. 87-93, 2009. 


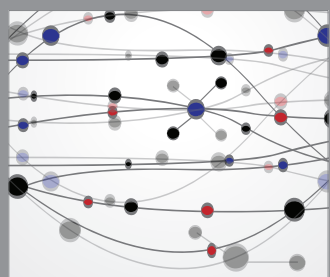

The Scientific World Journal
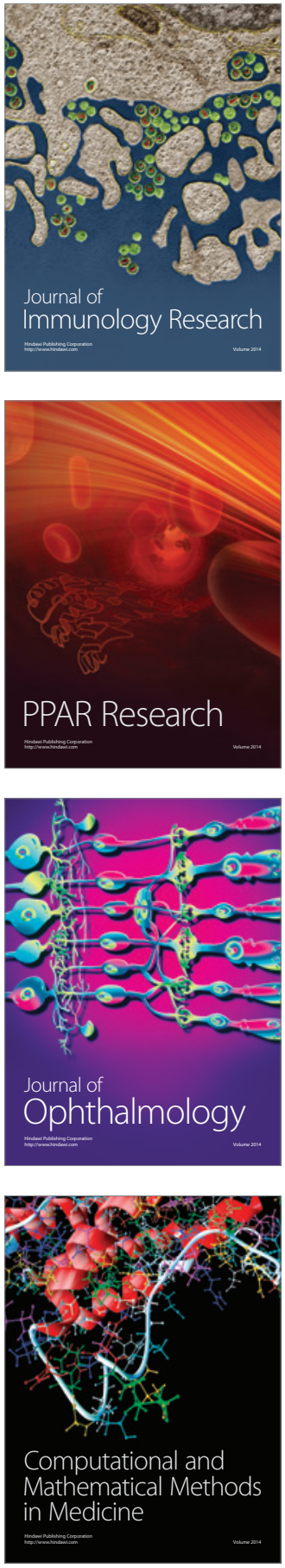

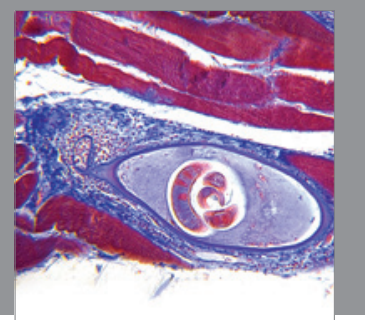

Gastroenterology

Research and Practice
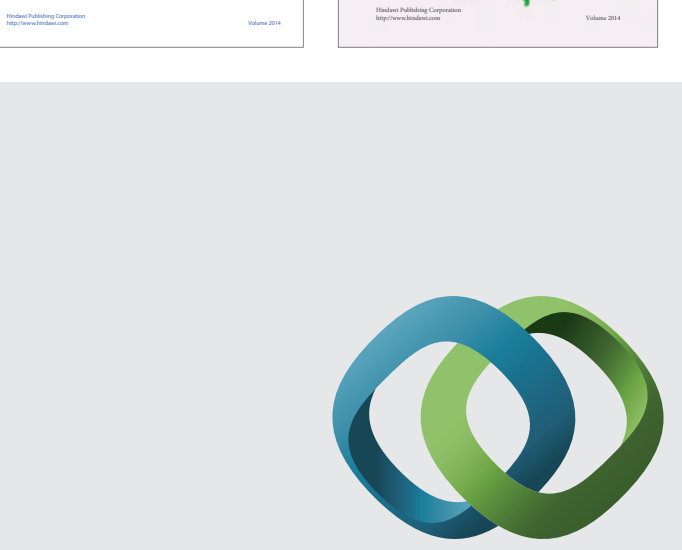

\section{Hindawi}

Submit your manuscripts at

http://www.hindawi.com
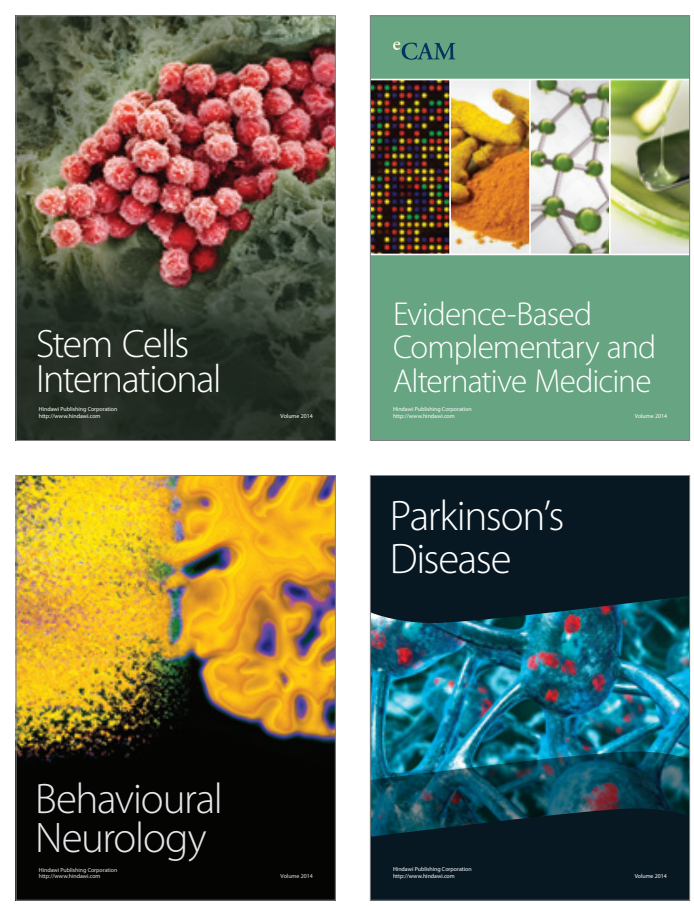

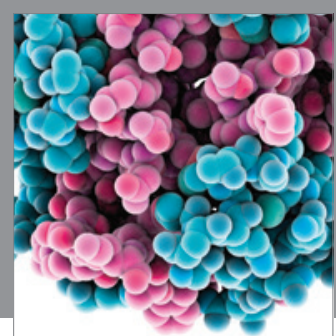

Journal of
Diabetes Research

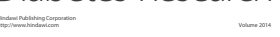

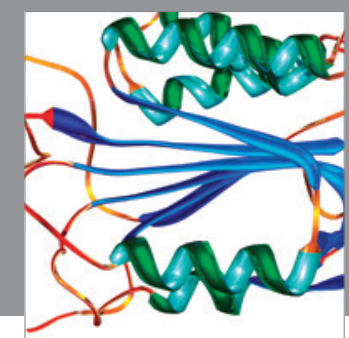

Disease Markers
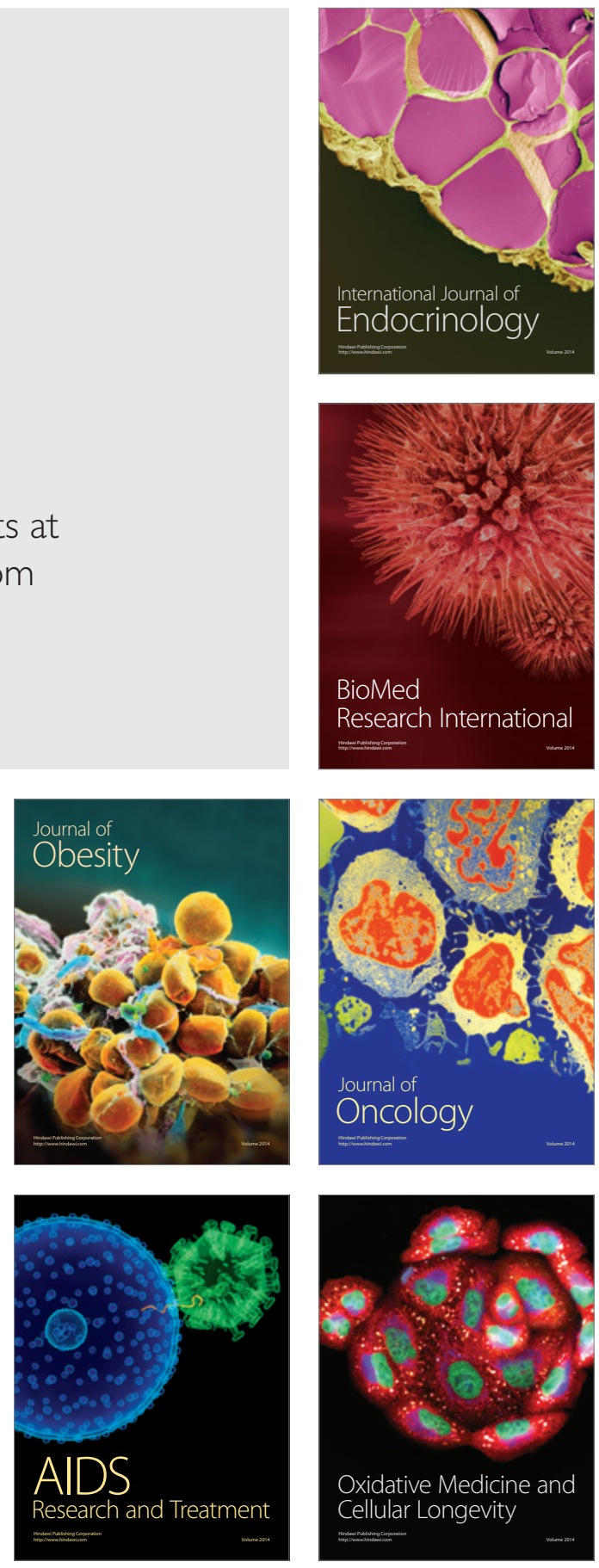